\title{
Water-retaining polymer as a soil conditioner in cowpea under water stress
}

Marilia Barcelos Souza Lopes, Helio Bandeira Barros, Aloísio Freitas Chagas Júnior, Manoel Mota dos Santos, Niléia Cristina da Silva, Rodrigo Ribeiro Fidelis*

\begin{abstract}
Cowpea is no longer a family-oriented crop. Today it is cultivated by medium and large farmers in the North and Northeast, due to their adaptation to edaphoclimatic conditions. The objective of this work was to evaluate the efficiency of hydrogel utilization in the retention and availability of water for the development and production of Cowpea beans when subjected to water stress. The experiment was conducted in a randomized block design with four replications in a $5 \mathrm{x}$ 2 factorial scheme, with five concentrations $\left(0,5,10,15\right.$ and $\left.20 \mathrm{~kg} \mathrm{ha}^{-1}\right)$ and two sources of hydrogels (Hydroplan-EB HyC and Polim-Agri). The cowpea cultivar used was BRS Vinager. The following characteristics were evaluated: number of pods per plant; Number of grains per pod; Pod length: one hundred grain mass and grain yield. The data were submitted to analysis of variance, with the application of the test $\mathrm{F}$. Regression analysis was performed with the help of the SISVAR computer system. The use of hydrogel was an alternative to reduce losses resulting from the action of water stress; the concentrations of hydrogels between 15 and $18 \mathrm{~kg} \mathrm{ha}^{-1}$ resulted in higher number of pods per plant, number of grains per pod, the mass of one hundred grains and yields of grains.
\end{abstract}

Keywords: Management, dry, summer, Vigna unguiculata (L.).

\section{Introduction}

The cowpea [Vigna unguiculata

(L.) Walp.] is a legume of easy adaptation, being cultivated in the tropical regions of the African, Asian and American continents. Brazil has emerged as the third world producer of cowpea beans, with a highlight on the north and northeast regions, which cultivate a large part of the beans produced in Brazil, with a significant social contribution to these regions as a source of employment and a constituent of human consumption (Bezerra et al., 2008).

Due to the characteristic of a comprehensive adaptation to edaphoclimatic conditions, cowpea beans emerged as a cultivation option in the consolidation of the new agricultural frontier called MATOPIBA (Maranhão, Tocantins, Piauí, and Bahia). Farmers have introduced cowpea beans in the off-season after harvesting soybeans or rice (areas of the first year) at the end of the rainy season. Under these conditions, cowpea develops well because it has a short vegetative cycle, is not very demanding in nutrition and water sources, using the residual nutrients of the predecessor crop, guaranteeing extra income to the farmers (Bertini et al., 2009).

According to Alves et al. (2009), the average productivity of cowpea in Brazil ranges from 400 to $500 \mathrm{~kg} \mathrm{ha}^{-1}$, which is well below its productive potential, which is around six tons per 
hectare. During the last years, the production has presented great variations mainly in regions whose production processes are directly dependable on the climate, as in the region of MATOPIBA where the cultivation of the beans is done under a rainfed regime, which is highly dependent on rainfall (Vale et al., 2015).

Water stress is a situation familiar to many cultures and is one of the factors that most affect agricultural production, affecting virtually all aspects related to plant development. The frequency and intensity of water deficiency are among the main limiting factors of world agricultural production (Damatta, 2007).

New techniques have been studied to make feasible the cultivation of annual cultivars in regions that face meteorological adversities. Hydrogels are defined as three-dimensional polymeric networks that can retain a significant amount of water within their structure and swell, without dissolution (Rui et al., 2007). In this context, this gel may be interesting, acting as regulators of water availability for crops, increasing local productivity and minimizing production costs. Its soil addition optimizes water availability, reduces percolation losses and nutrient leaching, and improves aeration and soil drainage, accelerating root and aerial plant development (Câmara et al., 2011; Navroski et al., 2015).

However, scientific information on the use of these polymers as soil conditioners for the cultivation of annual crops is scarce. Thus, the present work had as objective to evaluate the efficiency of hydrogel utilization in the retention and availability of water for the development and production of cowpea bean culture when cultivated under water deficiency.

\section{Materials and Methods}

The experiment was carried out in the southern state of Tocantins, at the experimental station of the Federal University of Tocantins, Gurupi Campus, on $01 / 26 / 2016$, harvest period of 2015/2016, located at latitude 11 $1^{\circ} 43^{\prime} 45^{\prime \prime}$ $\mathrm{S}$ and longitude of $49^{\circ} 04^{\prime}$ 07" W, at $280 \mathrm{~m}$ altitude. The soil was classified as Dystrophic Red - Yellow Latosol (EMBRAPA, 2013). According to the classification of Köppen Aw/As (1948), the climate of the region is mesothermic type with summer rains and dry winter. The meteorological data regarding the period of conduction of the experiments are displayed in Figure 1.

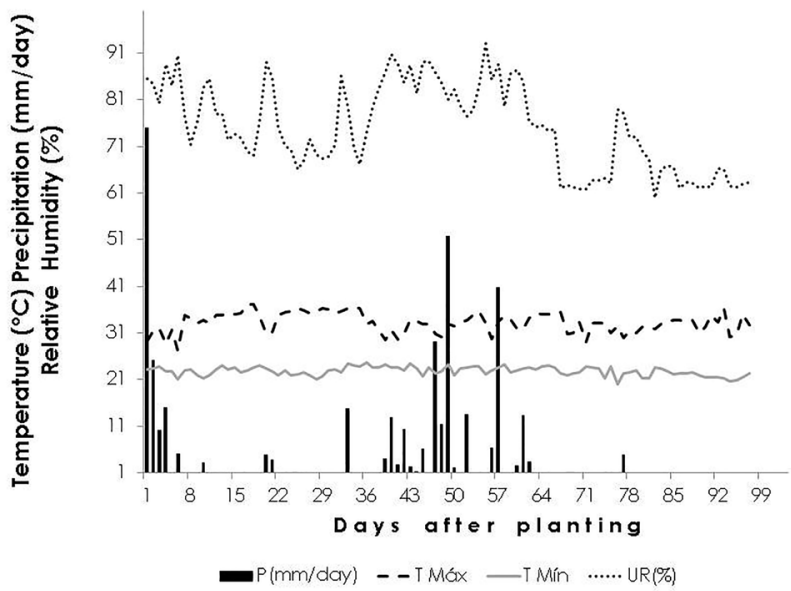

Figure 1. Pluvial precipitation ( $\mathrm{mm})$, and maximum and minimum temperatures $\left({ }^{\circ} \mathrm{C}\right)$ and relative air humidity (\%), occurred during the cowpea bean cultivation under the hydrogel influence, in the cropping season of 2015/2016 (IMET, 2016).

Prior to the installation of the experiment, soil samples were collected from the $0-20 \mathrm{~cm}$ layer depth to characterize the chemical and physical attributes. Soil analysis indicated $\mathrm{pH}$ values in $\mathrm{CaCl}_{2}=5.3 ; \mathrm{M} . \mathrm{O}(\%)=1.7 ; \mathrm{P}$ (Mehlich) = $10.4 \mathrm{mg} \mathrm{dm}^{-3} ; \mathrm{K}=71 \mathrm{mg} \mathrm{dm}^{-3} ; \mathrm{Ca}+\mathrm{Mg}=2.8 \mathrm{cmol}_{\mathrm{c}}$ $\mathrm{dm}^{-3} ; \mathrm{H}+\mathrm{Al}=2.2 \mathrm{cmol}_{\mathrm{c}} \mathrm{dm}^{-3} ; \mathrm{Al}=0.0 \mathrm{cmol}_{\mathrm{c}} \mathrm{dm}^{-3} ; \mathrm{SB}$ $=2.98 \mathrm{cmol}_{\mathrm{C}} \mathrm{dm}^{-3} ; \mathrm{V}=58 \% ; 715 \mathrm{~g} \mathrm{~kg}^{-1}$ of sand; 50 $\mathrm{g} \mathrm{kg}^{-1}$ of silt and $235 \mathrm{~g} \mathrm{~kg}^{-1}$ of clay.

For the study, the cowpea bean cultivar BRS Vinagre, with different concentrations of hydrogel and sources of the commercial product (hydrogel - conditioner of soil that retains water and nutrients for the plants) was used. The statistical design adopted was a randomized block design with four replicates, in a $5 \times 2$ factorial scheme, 
with five product concentrations $(0,5,10,15$ and $20 \mathrm{~kg} \mathrm{ha}^{-1}$ ) and two hydrogel sources. Hydrogel sources were: Hydroplan ( $\mathrm{H} 1$ ) appearance fine white powder, insoluble in water, with particles $<0,5 \mathrm{~mm}$, with absorption capacity up to 370 times its mass in water and 100 times its volume, Polim-Agri (H2) polymer belongs to the company POLIM-AGRI PP, Acrylamide/Potassium acrylate Copolymer derivative, granular, water-insoluble solid appearance, with particles ranging from $1-0.5 \mathrm{~mm}$.

Each experimental unit consisted of four $4.0 \mathrm{~m}$ long lines spaced $0.5 \mathrm{~m}$ apart. As a useful area, the two central lines were used, ignoring $0.50 \mathrm{~m}$ from the ends of each line and eliminating the two lateral lines, taking $3.0 \mathrm{~m}$ long lines, in an area of $3.0 \mathrm{~m}^{2}$. The seeds were treated with Standak ${ }^{\circledR}$ Top product equivalent to $25 \mathrm{~g}$ i.a. Pyraclostrobin, $225 \mathrm{~g}$ i.a. Thiophanate Methyl and $250 \mathrm{~g}$ i.e. Fipronil, following recommendations for the culture. Base fertilization was performed with $300 \mathrm{~kg} / \mathrm{ha}^{-1}$ of super-simple (20\%) and $34 \mathrm{~kg} / \mathrm{ha}^{-1}$ of Potassium Chloride (60\%) based on soil analysis and subsequently hydrated hydrogel proportion of $1 \mathrm{~g}$ per $400 \mathrm{~mL}$ of water and applied to each seeding line. Farming aspects followed the necessary for crop cultivation.

To verify the effect of the hydrogel on the development and production of cowpea, the following characteristics were evaluated: number of pods per plant - obtained by counting the total number of pods per plant of five plants randomly chosen in the useful area of each experimental unit; number of grains per pod obtained by counting the total number of grains from 20 pods; mass of 100 grains - obtained from a sample of 100 seeds per plot and correcting moisture to 13\%; grain yield - in grams, obtained after harvesting, threshing and weighing the grains, correcting for $13 \%$ of humidity and converted to $\mathrm{kg} \mathrm{ha}^{-1}$.

Experimental data were submitted to variance analysis. The means were compared by the Tukey test at $5 \%$ probability. The effects of hydrogel doses were evaluated by regression analysis using the SISVAR statistical program (Ferreira, 2011).

\section{Results and Discussion}

Table 1 displays the results of the average squares of the statistical analyzes obtained in the experiment. The number of grains per pods, grain mass, and productivity produced significant differences at $1 \%$ probability levels according to the variation of hydrogel concentration. The number of pods per plants have not presented any effect of treatments.

Table 1. Analysis of variance for number of pods per plant (NPP), number of grains per pod (NGP), Mass of 100 grains (M100) and yield (Yield), in cowpea bean cultivar with five concentrations and two hydrogel sources. Gurupi, TO. $2015 / 2016$

\begin{tabular}{|c|c|c|c|c|c|}
\hline Soure & D.F & NPP & NGP & M100 & Yield \\
\hline Repetition & 3 & 3.542 & 65.025 & 0.729 & 874,726 \\
\hline Hydrogel $(\mathrm{H})$ & 1 & $0.105^{\mathrm{ns}}$ & $3028.96^{\mathrm{ns}}$ & $0.003_{* *}^{\text {ns }}$ & $195.983^{\text {ns }} *$ * \\
\hline Concentration (C) & 4 & $7.339^{\text {ns }}$ & $3028.962^{* *}$ & $0.964^{* *}$ & $19594.523^{* *}$ \\
\hline $\mathrm{C} \times \mathrm{H}$ & 4 & $0.109^{\mathrm{ns}}$ & $34.212^{\mathrm{ns}}$ & $0.023^{\text {ns }}$ & $74.224^{\text {ns }}$ \\
\hline Residue & 27 & 10.178 & 4074.184 & 0.201 & 299.971 \\
\hline C. V. (\%) & & 3.8 & 8.6 & 3.45 & 5.33 \\
\hline Mean & & 8.373 & 167.720 & 13.036 & 325.086 \\
\hline
\end{tabular}

No significant effect was observed for hydrogel source and interaction (concentration $x$ source) on any of the evaluated characteristics, due to the similarity of the polymers, as regards their grain size, polymer chain structure, crosslinking density, acrylamide quantity, and others. Brito et al. (2013) explain that the tumescence process of a hydrogel is governed by physical factors intrinsic to the 3D network and external factors. Some physical factors, such as the presence of hydrophilic groups in the structure of the polymer chain, lower density of crosslinking and high flexibility of the polymer network, contribute to a greater swelling of the material.

Figure 2 highlight the quadratic response observed as analyzing the number of pods per plant for both polymers tested (Figure 2). The concentration of $15 \mathrm{~kg}$ ha-l provided a more significant increase in the evaluated characteristic, obtaining a mean of 9.21 and 9.35 
pods per plant, resulting in a 35 and $38 \%$ increase about the control for $\mathrm{H} 1$ and $\mathrm{H} 2$, respectively. It is noteworthy that even the lowest concentration of the polymer tested favored an increase of 25 and $21.2 \%$ about the control. Mendes et al. (2007), studying two cultivars of cowpea that were submitted to water deficiency from the tenth to the 44th day after sowing (vegetative phase), obtained an average of 4.50 pods per plant. Figure 1 highlights a severe water deficit of
26 days in the vegetative phase (10 DAS). Stress in the vegetative phase causes changes such as reduction of leaf water potential, stomatal closure, reduction of photosynthetic rate, reduction of the development of the aerial part, acceleration of senescence, leaf abscission, reduces plant growth and consequently affects plant production factors (Pereira et al., 2012; Ferrari et al., 2015).

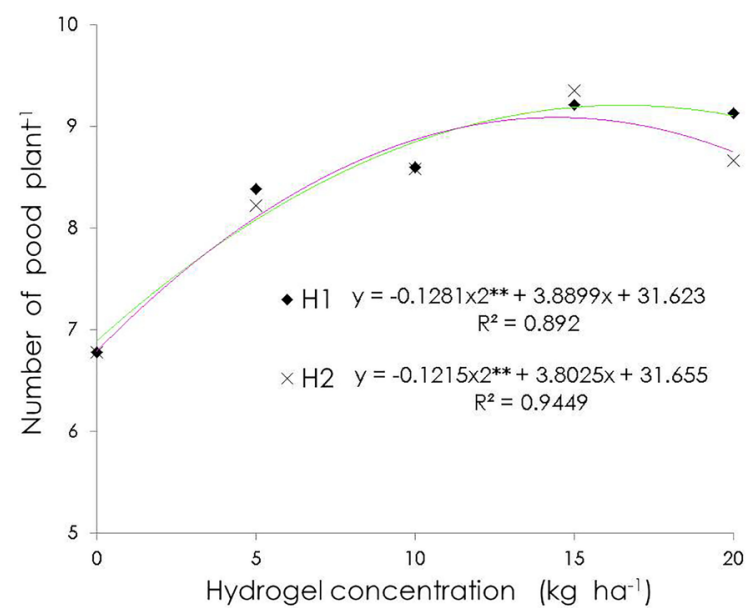

Figure 2. Number of pods per plant of cowpea bean cV. BRS Vinegar submitted to different concentrations $\left(0 ; 5 ; 10 ; 15 ; 20 \mathrm{~kg} \mathrm{ha}^{-1}\right)$ and commercial products ( $\mathrm{H} 1$ : Hydroplan; $\mathrm{H} 2$ : Polim-agri). ${ }^{\text {ns }}$ not significant; ** significant for $\mathrm{P} \leq 0.01$; * Significant for $\mathrm{P} \leq 0.05$, according to the $\mathrm{F}$ test.

As for the number of grains per pod characteristic (Figure 3) similar to that observed with the number of pods per plant, an increase up to the concentration of $15 \mathrm{~kg} \mathrm{ha}^{-1}$, with a yield of 15.66 and 16.6 grains by pods for the hydrogels $\mathrm{H} 1$ and $\mathrm{H} 2$, thus adjusting quadratic response for both evaluated polymers. The cowpea beans showed an increase of 14 and $21 \%$ in grain numbers when compared to the control. Freitas et al. (2013) when submitting the cowpea bean culture to 18 days of water stress under two cultivation forms (no-tillage and conventional) had 8.7 and 5.9 pods per plant, respectively. It is worth noting that the no-tillage system is considered a tool to reduce the risk that water deficit causes in crops. Even the same, the use of hydrogel as an alternative to minimize water stress in cowpea was $90 \%$ more efficient to increase the pods per plant than the notillage system in the work above, thus evidencing the efficiency of the hydrogel to make water available to the plants under conditions of water stress. Azevedo et al. (2002) explain that water- retaining polymers function as an alternative for situations where there is no water availability in the soil, water stress conditions or long periods of drought when low soil moisture adversely affects growth and plant development.

Analyzing the mass of 100 grains feature, we observed an increase up to the concentration of $15 \mathrm{~kg} \mathrm{ha}^{-1}$, reaching a mass of 13.41 and $13.30 \mathrm{~g}$ in one hundred grains for $\mathrm{Hl}$ and $\mathrm{H} 2$ hydrogels, respectively (Figure 4). Figure 1 displays a further severe water stress in the reproductive phase (grain filling) 65 days after emergence (DAE), totaling a cumulative of 35 days without significant rainfall (above $5 \mathrm{~mm}$ ). Therefore, the use of water-retaining polymers is efficient in providing a 28 and $23 \%$ increase in the hydrogel sources $\mathrm{H} 1$ and $\mathrm{H} 2$ when compared to the water-stressed control in the reproductive phase. Morando et al. (2014) stated that the availability of water is important, mainly, in two periods of the crop development, germinationemergence, and flowering-filling of grains. 


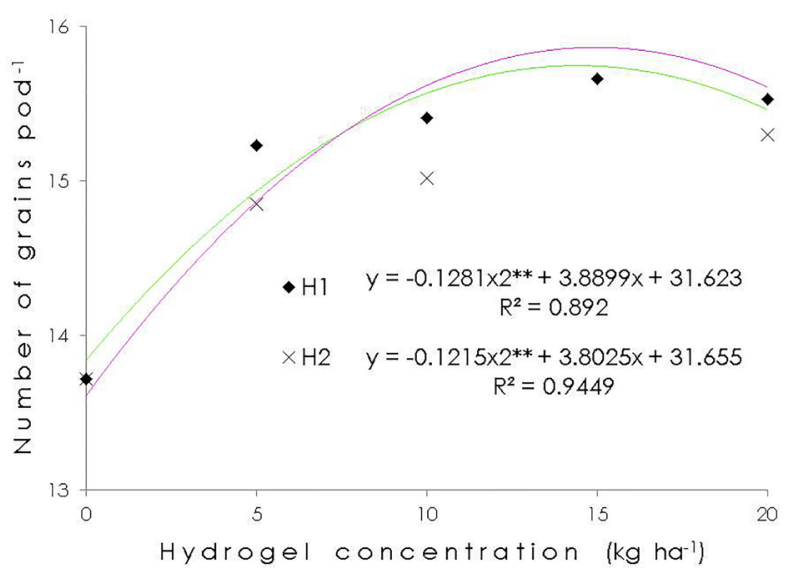

Figure 3. Number of grains per pod of cowpea bean $\mathrm{cv}$. BRS Vinagre submitted to different concentrations $\left(0 ; 5 ; 10 ; 15 ; 20 \mathrm{~kg} \mathrm{ha}^{-1}\right)$ and commercial products ( $\mathrm{H} 1$ : Hydroplan; $\mathrm{H} 2$ : Polim-agri). ${ }^{\text {ns }}$ not significant; " significant for $P \leq 0,01$; "significant for $\mathrm{P} \leq 0,05$, according to the F test.

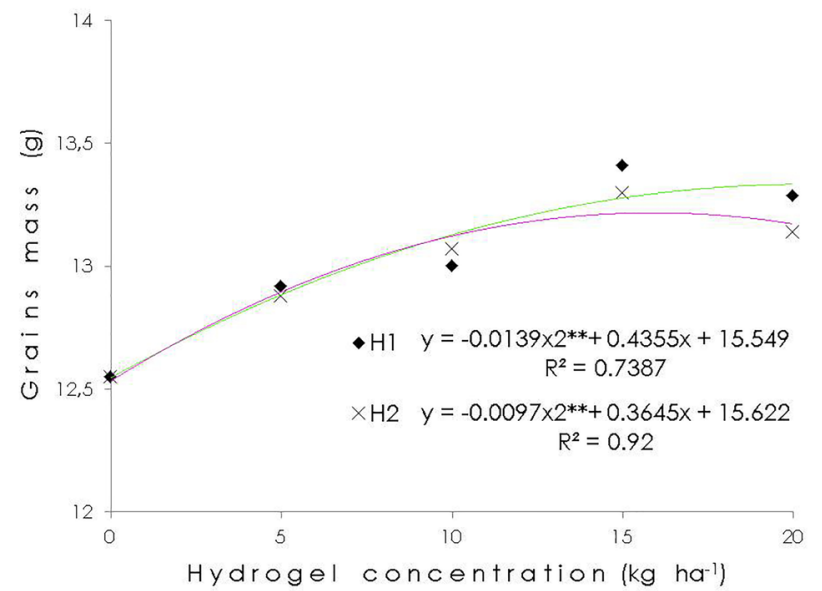

Figure 4. Mass of 100 grains of cowpea bean cV. BRS Vinagre submitted to different concentrations $\left(0 ; 5 ; 10 ; 15 ; 20 \mathrm{~kg} \mathrm{ha}^{-1}\right)$ and commercial products ( $\mathrm{H} 1$ : Hydroplan; H2: Polim-agri). ${ }^{\text {ns }}$ not significant; * significant for $\mathrm{P} \leq 0,01$; " significant for $\mathrm{p} \leq 0,05$, according to the $\mathrm{F}$ test.

For grain yield characteristic, we observed a quadratic behavior with increase in the production up to the concentration of 15.8 $\mathrm{kg} \mathrm{ha}^{-1}$, with averages of 380 and $394 \mathrm{~kg} \mathrm{ha}^{-1}$, for the hydrogel sources $\mathrm{H} 1$ and $\mathrm{H} 2$, respectively, representing an increase of 52 and $58 \%$ when compared to the control (Figure 5). Ramos et al. (2014) found a productivity reduction of over $77 \%$ in two cultivars of cowpea cultivated under intense water stress. Nascimento et al. (2011) and Endres et al. (2010) concluded that cultivars of cowpea cultivated under water deficit in the vegetative phases and grain filling showed a strong reduction in leaf water potential, leading to a high stomatal closure, resulting in a lower production of photoassimilates, leading to a lower productivity.
Therefore, considering the two severe water deficits (vegetative and reproductive phase) to which the cowpea culture was submitted, the efficiency of water-retaining polymers in the availability of water to the plants becomes evident. These results corroborate with those found by Mendonça et al. (2013), who stated that water-retaining polymers act to regulate water availability to crops during water stress, thus increasing productivity and minimizing costs of re-implantation of crops.

Another unusual factor for all evaluated characteristics is the decrease in the increment of the concentration of $20 \mathrm{~kg} \mathrm{ha}^{-1}$. Two factors may be contributing to this adverse effect of the high concentration, excess water during the intense rainy season, which associated with 


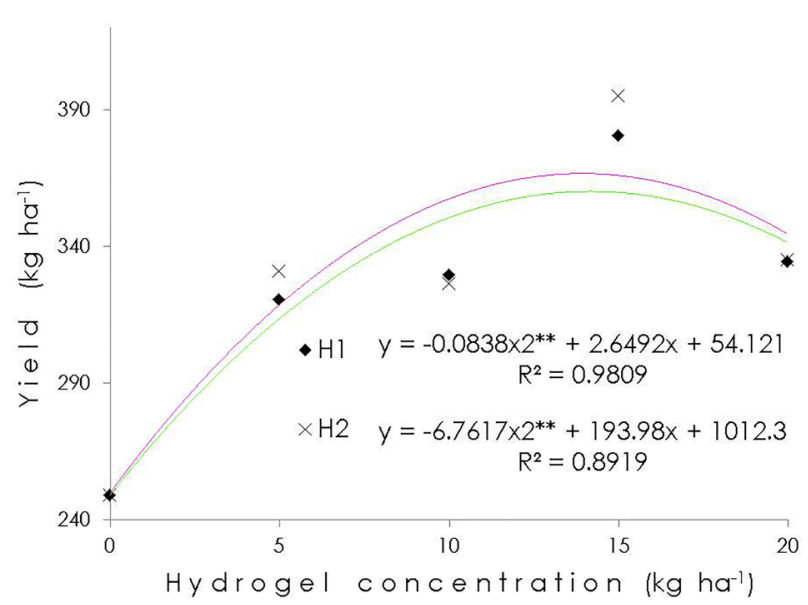

Figure 5. Grain yield of cowpea bean cv. BRS Vinagre submitted to different concentrations $\left(0 ; 5 ; 10 ; 15 ; 20 \mathrm{~kg} \mathrm{ha}^{-1}\right)$ and commercial products ( $\mathrm{Hl}$ : Hydroplan; $\mathrm{H} 2$ : Polim-agri). ${ }^{\text {ns }}$ not significant; " significant for $P \leq 0,01$; "significant for $P \leq 0,05$, according to the $F$ test.

the water retained in the polymer may have hindered soil aeration and root development. Hafle et al. (2008) and Sousa et al. (2013) illustrate in their studies that the growth of the roots of the perennial plants tends to decrease due to the excess of water caused by the high concentrations of the polymer, reducing aeration of the substrate. Another factor for associated to the reduction of the growth of the plants may be the high level of water-retaining polymers changing electrical conductivity and $\mathrm{pH}$ of the soil. These modifications may limit the absorption of some nutrients. Navroski et al. (2016) observed that the higher concentrations of the waterretaining polymer cause an increase in the electrical conductivity due to the accumulation of salts retained in the polymer and the rise in the $\mathrm{pH}$ in the substrate of forest seedlings.

\section{Conclusions}

The use of hydrogel is an alternative to reduce losses resulting from the action of water stress;

The hydrogel concentrations between 15 and $15.8 \mathrm{~kg} \mathrm{ha}^{-1}$ resulted in higher plant height, number of pods, mass of one hundred grains and grain yields, making it advisable to increase the production of cowpea when cultivated under a hydric deficit.

\section{References}

Alves, J.M., Araújo, N.P., Uchôa, S.C.P., Albuquerque, J.A.A., Silva, A.J., Rodrigues, G.S., Silva, D.C.O. 2009. Agro-economic evaluation of the production of cowpea cultivars in a consortium with cassava cultivars in Roraima. Revista Agro@ambiente 3: 15-30.

Azevedo, T.L.F., Bertonha, A., Gonçalves, A.C.A. 2002. Use of hydrogel in agriculture. Revista do Programa de Ciências Agro-Ambientais 1: 23-31.

BERTINI, C.H.C.M., TEÓFILO, E.M., DIAS, F.T.C. 2009. Genetic divergence between cowpea accesses of the UFC germplasm bank. Revista Ciência Agronômica 40: 99-105.

Bezerra, A.A.C., Távora, J.F.A.F., Freire Filho, F.R., Ribeiro, V.Q. 2008. Morphology and grain production in modern lines of cowpea submitted to different population densities. Revista da Biologia e Ciências da Terra 8: 85-93.

Brito, C.W.Q., Rodrigues, F.H.A., Fernandes, M.V.S., Silva, L.R.D., Ricardo, N.M.P.S.; Feitosa, J.P.A.; Muniz, E.C. 2013. Synthesis and characterization of composite hydrogels from acrylamide-acrylate and kaolin copolymers: effect of the constitution of different kaolins from the Brazilian Northeast. Quimica Nova 36: 40-45.

Câmara, G.R., Reis, D.F., Araújo, G.L., Cazotti, M.M., Donatelli Júnior, E.J. 2011. Evaluation of the development of tropical Conilon coffee tree using water-retaining polymers and different irrigation shifts. Enciclopédia Biosfera 7: 135-146.

Damatta, F.M. 2007. Ecophysiology of tropical tree crops: am introduction. Brazilian Journal of Plant Physiology 19: 239-244.

EMBRAPA - National Soil Research Center. Brazilian system of soil classification. Embrapa, Brasília, 2013.

Endres, L., Souza, J.L., Teodoro, L., Marroquim, P.M.G., Santos, C.M., Brito, J.E.D. 2010.Gas exchange alteration caused by water deficit 
during the bean reproductive stage. Revista Brasileira de Engenharia Agrícola e Ambiental 14: 11-16.

Ferrari, E., Paz, A., Silva, A.C. 2015. Water deficit in soybean metabolism in early sowing in Mato Grosso.Nativa 3: 67-77.

Ferreira, D.F. 2011. Sisvar: a computer statistical analysis sistem. Ciência e Agrotecnologia 35: 1039-1042.

Freitas, R.M.O., Dombroski, J.L.D., Freitas, F.C.L., Nogueira, N.W., Procópio, I.J.S. 2013. Production of cowpea under summer effect in no-tillage and conventional systems. Semina: Ciências Agrárias 34: 3683-3690.

Köppen, W. 1948. Climatologia: con un estúdio de los climas de la terra. Fondo de Cultura Económica, Mexico, 479 p.

Hafle, O.M., Cruz, M.C.M., Ramos, J.D., Ramos, P.S., Santos, V.A. 2008. Production of sweet passion fruit seedlings through the cutting using water-retaining polymer. Revista Brasileira de Ciências Agrárias 3: 232-236.

Nascimento, S.P., Bastos, E.A., Araújo, E.C.E., Ferreira Filho, F.R., Silva, E.M. 2011. Tolerance to water deficit in cowpea genotypes. Revista Brasileira de Engenharia Agrícola e Ambientel 15: 853-860.

Navroski, C.M., Araújo, M.M., Pereira, A.O.P., Fior, C.S. 2016. Influence of the water-retaining polymer on the characteristics of the commercial substrate for the production of forest seedlings. Interciencia 41: 357-361.

Navroski, M.C., Araújo, M.M., Reininger, L.R.S., Muniz, M.F.B., Pereira, M.O. 2015. Influence of hydrogel on growth and nutrient content of seedlings Eucalyptus dunnii. Floresta 45: 315-328, 2015.

Mendes, R.M.S., Távora, F.J.A.F., Pitombeira, J.B., Nogueira, R.J.M.C. 2007. Source-drain relations in string beans subjected to water deficiency. Revista Ciência Agronômica 38: 95-103.

Mendonça, T.G., Urbano, V.R., Cabral, F.F.P., Bacalhau, F.B., Souza, C.F. 2013. Hydrogel as an alternative in increasing soil water storage capacity. Water Resources and Irrigation Management 2: 87-92.

Morando, R., Silva, A.O., Carvalho, L.C., Pinheiro, M.P.M.A. 2014. Water Deficit: Effect on Soybean Culture. Journal of Agronomic Sciences 3: 114129.

Pereira, J.W., Melo Filho, P.A., Albuquerque, M.B., Nogueira, R.J.M., Santos, R. C. 2012. Biochemical changes in peanut genotypes subjected to moderate water deficit. Revista Ciência Agronômica 43: 766-773.

Ramos, H.M.M., Bastos, E.A., Cardoso, M.J., Ribeiro, V.Q., Nascimento, F.N. 2014. Productivity of green beans of cowpea under different water regimess. EngenheiraAgrícola 34: 683-694.

Rui, L., Mingzhu, L., Lan, W. 2007.Controlled release NPK compound fertilizer with the function of water retention. Reactive and Functional Polymers 67: 769-779.

Sousa, G.T.O., Azevedo, G.B., Sousa, J.R.L., Mews, C.L., Souza, A.M. 2013. Incorporation of waterretentive polymer into the seedling production substrate of Anadenanthera peregrina (L.) Speg. Enciclopédia Biosfera 9: 1270-1278.

Vale, N.M., Barili, L.D., Oliveira, H.M., Carneiro, J.E.S., Carneiro, P.C.S., Silva, F.L. 2015. Selection of parents regarding the precocity and productivity of "Carioca" beans. Pesquisa Agropecuária Brasileira 50: 141-148. 